\title{
Experimental Study of the Combustion of Kerosene and Binary Surrogate in the Model Combustion Chamber
}

\author{
Sergey S. Matveev, Ivan V. Chechet, Aleksander S. Semenikhin, Valerii Y. Abrashkin, \\ Sergey V. Lukachev, and Sergey G. Matveev \\ Scientific and Educational Centre of Fluid Dynamics Research, Samara National Research University, Samara, Russia \\ Correspondence should be addressed to Sergey S. Matveev; matveev@ssau.ru
}

Received 22 March 2017; Revised 27 July 2017; Accepted 31 October 2017; Published 10 December 2017

Academic Editor: Kalyan Annamalai

Copyright (c) 2017 Sergey S. Matveev et al. This is an open access article distributed under the Creative Commons Attribution License, which permits unrestricted use, distribution, and reproduction in any medium, provided the original work is properly cited.

\begin{abstract}
The purpose of this paper is to conduct experimental research of hazardous substance emissions at the simulated combustion chamber output. The experiment was carried in a simulated combustion chamber. The combustion chamber included a burner device; a liquid fuel feed system; and a flame tube with two rows of mixing holes and one row of cooling holes. The combustion chamber operation mode was $\varphi=0.435, T_{\text {preheat }}=423 \mathrm{~K}$, and the atmospheric pressure. The liquid fuel burn rate was $0.77 \mathrm{~g} / \mathrm{s}$. The pressure ratio in the combustion chamber remained constant at $\Delta P=3 \%$. Two types of fuel were used: aviation kerosene of Russia's TS- 1 brand and the fuel surrogate was $n$-decane mixture $(\mathrm{C} 10 \mathrm{H} 22)$ with benzene additions $(\mathrm{C} 6 \mathrm{H} 6)$. The benzene additions were $5 \%$ through $30 \%$ (n-decane/benzene: 95/5, 90/10, 85/15, 80/20, 75/25, and 70/30).
\end{abstract}

\section{Introduction}

A combustion chamber is one of the main parts of a gas-turbine engine defining its emission characteristics. At present, the problem of gas-turbine engine emissions has been primarily solved by means of semiempirical calculations and of prototype experimental development. This approach is labour intensive and gives little information on the processes inside the chamber which precludes implementation of the ICAO standards.

Modern techniques of designing and debugging combustion chambers of gas-turbine engines should use computational fluid dynamics (CFD). CFD calculations should be based on simultaneous solution of gas dynamics equations and detailed chemical kinetics. With the current level of computational power, solution of such problems in the nearest decades does not seem possible. Another solution could be employing hybrid methods. A hybrid method is supposed to solve each problem individually and then combine them into a single algorithm. Simulation of chemical kinetics is not conceivable without using detailed and reduced mechanisms of reaction. To develop kinetic mechanisms it is necessary to know the exact composition of the initial fuel. The main type of gas-turbine engine fuel is aviation kerosene. Kerosene consists of dozens of separate hydrocarbon components. Its composition may vary depending on the raw materials and manufacturers. Numerical simulation requires a mixture consisting of the known components and containing a limited number of chemical constituents. These mixtures are called surrogates. A surrogate should reproduce the main characteristics of real fuel.

A detailed kinetic mechanism of surrogate oxidation should imitate the essential chemical properties of kerosene. Reduced mechanisms are used for calculating gas dynamics and should identically describe kerosene physical properties as well as to accurately predict temperature distribution and recovered fuel concentration in the combustion chamber.

To develop hybrid methods of CFD simulation of combustion chamber environmental performance, it is necessary to solve two main problems:

(1) Tailoring the aviation kerosene surrogate. The surrogate should properly reproduce kerosene chemical or physical properties.

(2) Developing detailed and reduced mechanisms of surrogate oxidation. 
TABLE 1: Composition (volume fraction of components) of conventional aviation fuels.

\begin{tabular}{lcccc}
\hline Component & JP-4 & JP-5 & JP-7 & JP-8, Jet-A, TC1 \\
\hline Alkanes, vol\% & 59 & 45 & 65 & 60 \\
Cycloalkanes, vol\% & 29 & 34 & 32 & 20 \\
Alkenes, vol\% & 2 & 2 & - & 2 \\
Aromatics, vol\% & 10 & 19 & 3 & 18 \\
Sulphur, ppm & 370 & 470 & 60 & 490 \\
\hline
\end{tabular}

The solution of these problems (together or in combination) could provide a solid foundation for developing a hybrid method. This research has focused on solving the first problem.

\section{Kerosene Surrogate}

All components of complex fuels can be divided into several structural classes. These are alkanes (saturated hydrocarbons having a linear or a branched structure), alkenes (hydrocarbons with double bonds), cycloalkanes (saturated hydrocarbons containing a ring), and aromatic hydrocarbons (molecules containing benzene rings) [1,2]. Table 1 represents the average composition of some aviation fuels [2]. The greater part of the fuel are alkanes: their total amount reaches $65 \%$, and together with cycloalkanes they account for $79-97 \%$. A considerable share (up to $20 \%$ ) is constituted by aromatic hydrocarbons. On the other hand, the concentration of alkenes in the fuel is insignificant.

Several works [3-10] suggest a large number of surrogates for aviation kerosene Jet-A which is commonly used in the USA. Jet-A is analogous to Russian kerosene TC1. The above works present kinetic mechanisms of simulating ignition and burning of these surrogates. The simplest surrogates are monopropellant fuels. The authors of $[3,11]$ were simulating Jet-A burning with $n$-decane as a surrogate. Cooke et al. [12] used $n$-dodecane for the same purpose and demonstrated an important role of alkyl hydroperoxide radicals in hydrocarbon slow oxidation.

As kerosene contains up to $20 \%$ aromatic hydrocarbons having their own specific features in oxidation kinetics, these components are bound to be included into the surrogate. The following aromatic compounds can be considered as possible options: benzene, toluene, trimethylbenzene, $n$ propyl benzene, $n$-butyl benzene, and others. Lindstedt and Maurice [4] showed numerically that the kerosene flame structure can be described with reasonable accuracy by a surrogate: $89 \% n$-decane and $11 \%$ aromatic hydrocarbons (benzene, toluene, and ethyl benzene).

Most works on surrogates deal with studying and comparing their fundamental features: laminar flame speed, ignition delay time, and so forth. This research has compared the kerosene combustion products and its surrogate while burning in real equipment. The surrogate consisted of n-decane and benzene in various proportions: $100 \%$ n-decane, $95 / 5 \%$, $90 / 10 \%, 85 / 15 \%, 80 / 20 \%$, and 75/25\% n-decane/benzene.

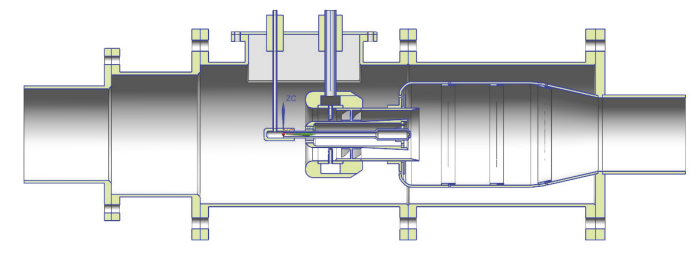

FIGURE 1: Simulated combustion chamber.

\section{Experimental Setup}

The experiment was carried out in a simulated combustion chamber (Figure 1), which has a burner device, a liquid fuel supply system, and a flame tube with two rows of mixing holes and one row of cooling holes. The combustion chamber operation mode was $\varphi=0.435, T^{*}=423 \mathrm{~K}$, and the atmospheric pressure. The liquid fuel burn rate is $0.77 \mathrm{~g} / \mathrm{s}$. The pressure ratio in the combustion chamber that remained constant at $\Delta P=3 \%$.

$$
\Delta P=\frac{P_{\text {in }}-P_{\text {out }}}{P_{\text {in }}} * 100 \%
$$

$P_{\text {in }}$ is total pressure at inlet of combustion chamber (const); $P_{\text {out }}$ is total pressure at outlet of combustion chamber (const).

Experimental trials were carried out at the hightemperature experimental setup with a simulated combustion chamber. The experimental setup carries a flow meter made by SMC, a pneumatic throttle with nonreturn valves, mass flow meters/controllers of EL-FLOW ${ }^{\circledR}$ series made by Bronkhorst High-Tech, a liquid fuel supply system and an incoming air heater. The general view of the hightemperature setup connected to the fuel line and the air lines is presented in Figure 2.

To equalize the velocity field, an equalizing device is provided at the heater input. For the main fuel supply, there is a pumping system. For the surrogate fuel supply, there is a pressure feed system. The pressure feed system consists of the following: a fuel tank (10 litres), a fuel tank pressurization and fuelling system, and a fine filter for composite propellants.

The high-pressure pump control system makes it possible to change the output pressure in the range between 0.4 and $1.5 \mathrm{MPa}$ at a flow rate of at least $250 \mathrm{l} / \mathrm{h}$. 
TABLE 2: Experimental case.

\begin{tabular}{|c|c|c|c|c|c|c|}
\hline No. & Fuel composition & $\varphi$ & $T^{*}$ & $P_{K}$ & $G_{\text {air }}$ & $G_{\text {fuel }}$ \\
\hline 1 & Kerosene TS- 1 brand & & & & & \\
\hline 2 & Kerosene TS-1 brand & & & & & \\
\hline 3 & n-Decane & & & & & \\
\hline 4 & n-Decane/benzene (95/5\%) & & & & & \\
\hline 5 & n-Decane/benzene (90/10\%) & 0.548 & $423 \mathrm{~K}$ & $1 \mathrm{~atm}$ & $0.021 \mathrm{~kg} / \mathrm{s}$ & $0.00081 \mathrm{~kg} / \mathrm{s}$ \\
\hline 6 & n-Decane/benzene $(85 / 15 \%)$ & & & & & \\
\hline 7 & n-Decane/benzene $(80 / 20 \%)$ & & & & & \\
\hline 8 & n-Decane/benzene $(75 / 25 \%)$ & & & & & \\
\hline 9 & n-Decane/benzene $(70 / 30 \%)$ & & & & & \\
\hline
\end{tabular}

For each experiment there were 8 samplings performed.

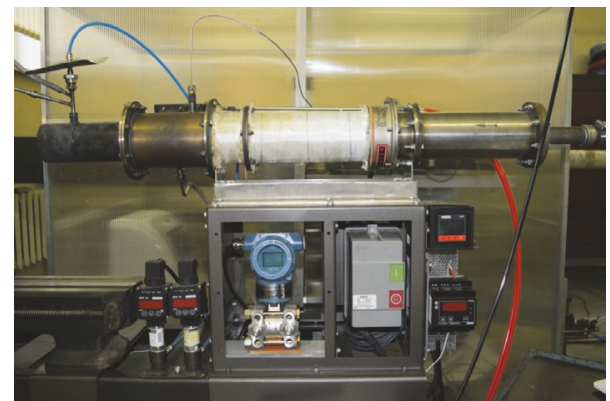

Figure 2: General view of the high-temperature setup.

The composition of combustion products was defined by the contact technique based on probe sampling. This method is currently the most developed one and is widely used in experimental practice.

The sample line (Figure 6) consists of a sampler (1), a Richter absorber (2), a pump (3) built into the SICKGMS-810 analyzer (4), Seger pipettes (5), and a GSB-400 gas meter (6). GSB-400 is used to estimate the volume $\left(V_{\Pi}, \mathrm{M}^{3}\right)$ and the flow rate $\left(Q_{\Pi}, \mathrm{M}^{3} / \mathrm{c}\right)$ of sampled gases.

The sample-from the sampling point to the Seger pipettes-was pumped with a pump built into the SICKGMS-810 analyzer. This sample line configuration allowed simultaneous sample pumping via Seger pipettes and its dehydration and analysis.

During sampling, the combustion products were pumped via the Seger pipettes at the flow rate of $Q_{\Pi}=(20-33) \cdot 10^{-6}$ $\mathrm{M}^{3} / \mathrm{c}$ with the volume equal to 20 pipette volumes. Obtained gas samples were analyzed using gas chromatography. The sampling was carried out at the output of the simulated combustion chamber. Table 2 shows the initial conditions for each experimental case.

\section{Results}

The experimental research has resulted in obtaining the relationship between the mass fraction of $\mathrm{CO} 2, \mathrm{CO}$, unburned hydrocarbons ( $\mathrm{CnHm}), \mathrm{O} 2, \mathrm{H} 2, \mathrm{H} 20, \mathrm{~N} 2$, and the benzene percentage in the surrogate (Figures 3-12). These figures also show the analysis results for the kerosene burning samples.

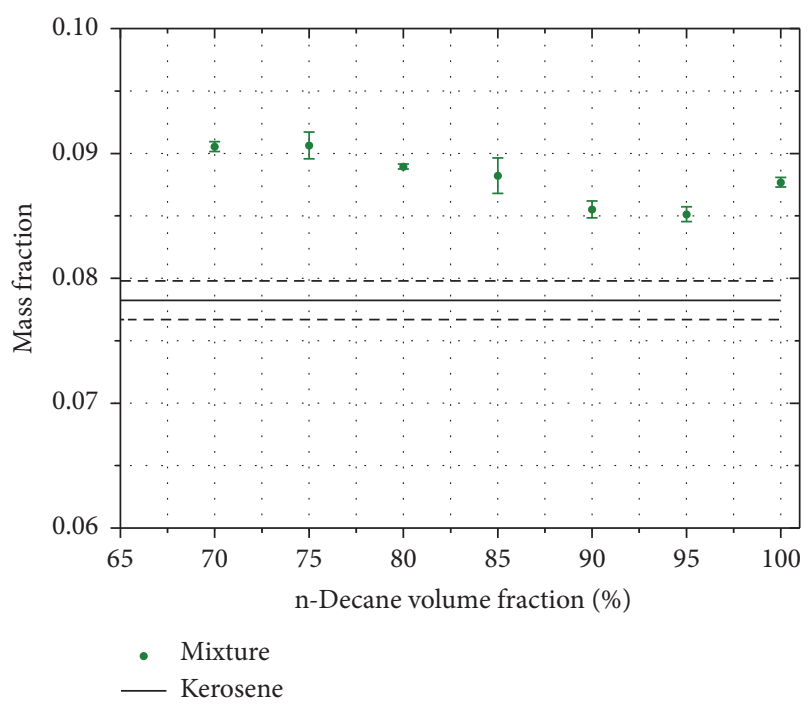

FIGURE 3: Comparison of mass fraction of $\mathrm{CO} 2$ for the surrogate and the kerosene burning.

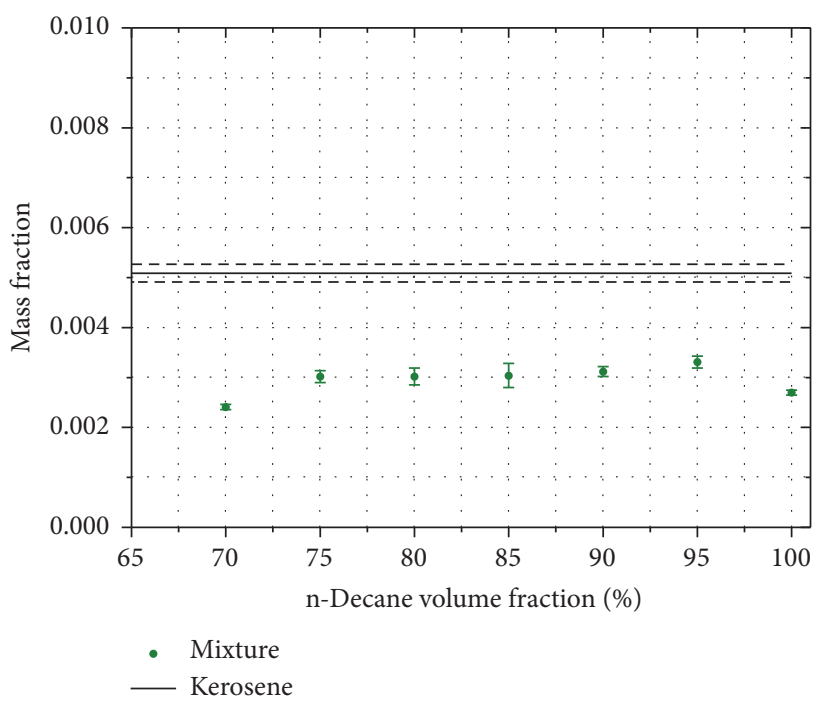

FIGURE 4: Comparison of mass fraction of $\mathrm{CO}$ for the surrogate and the kerosene burning. 


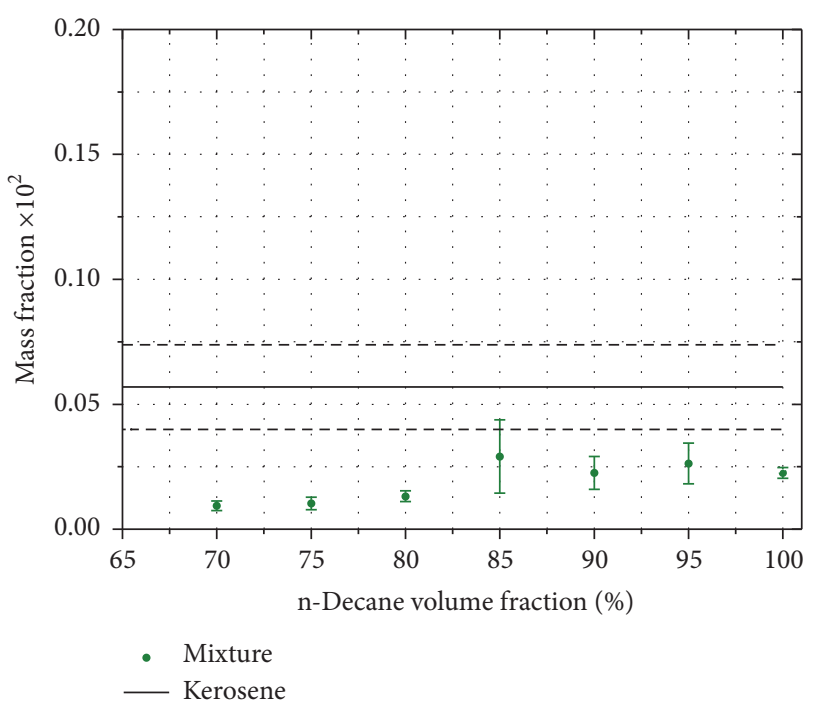

FIGURE 5: Comparison of mass fraction of unburned hydrocarbons $(\mathrm{CnHm})$ for the surrogate and the kerosene burning.

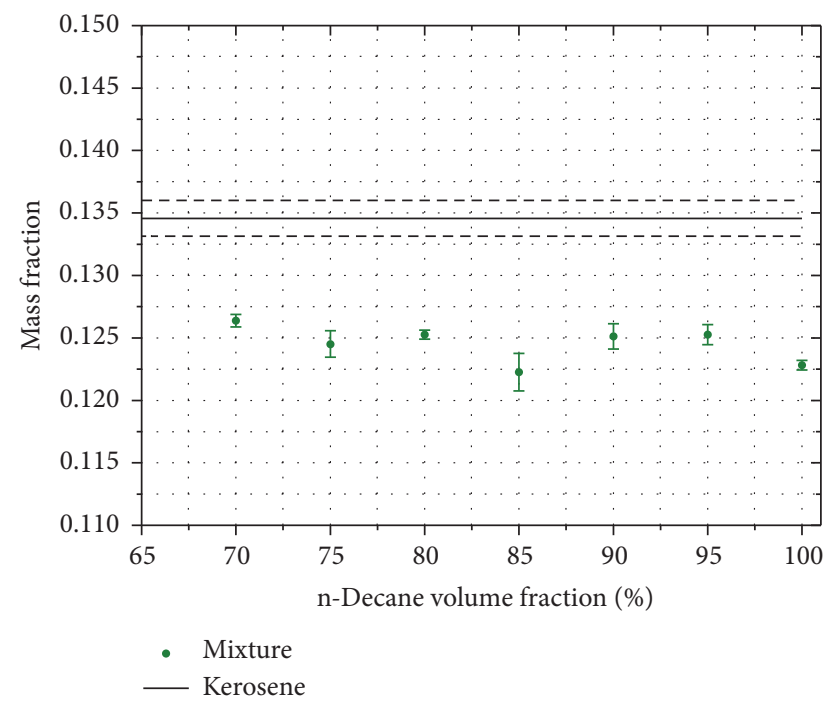

FIGURE 6: Comparison of mass fraction of $\mathrm{O} 2$ for the surrogate and the kerosene burning.

The presented figures show that combustion products of kerosene did not match any of the cases of the mixture in combustion. Averaged temperature at the outlet of the combustion chamber was the same for all cases of the mixture. But the combustion efficiency increased with increasing benzene content in the mixture. The combustion efficiency $(\eta)$ was calculated as the ratio of the enthalpy of the initial mixture to the enthalpy of products of incomplete combustion.

$$
\eta=\frac{H^{m}-H^{\mathrm{cp}}}{H^{m}} * 100 \%
$$

$H^{m}$ is enthalpy of mixture (benzene/n-decane/air); $H^{\mathrm{cp}}$ is enthalpy of combustion products.

Mixture consisting of benzene and n-decane has a lower evaporation temperature than kerosene. Increased benzene

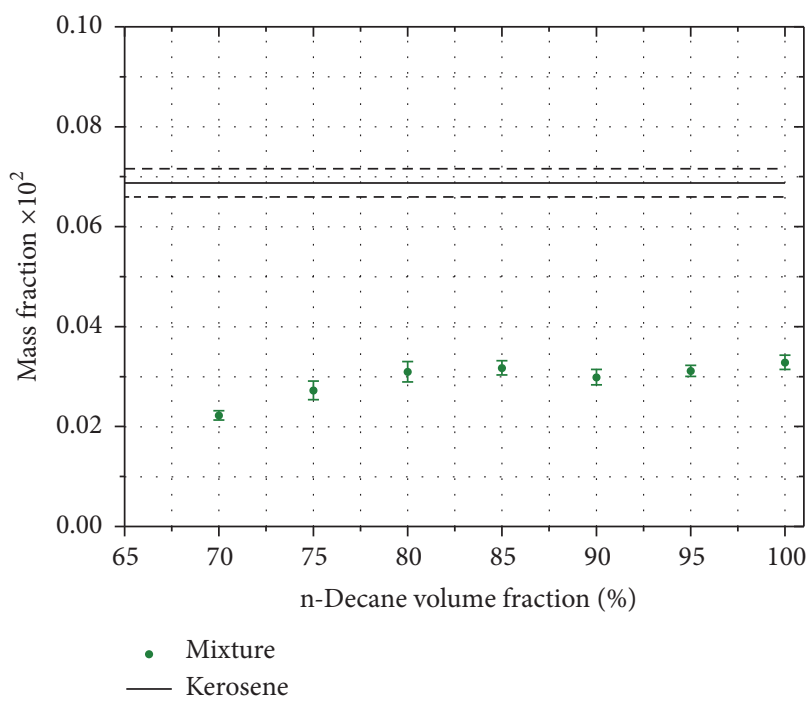

FIGURE 7: Comparison of mass fraction of $\mathrm{H} 2$ for the surrogate and the kerosene burning.

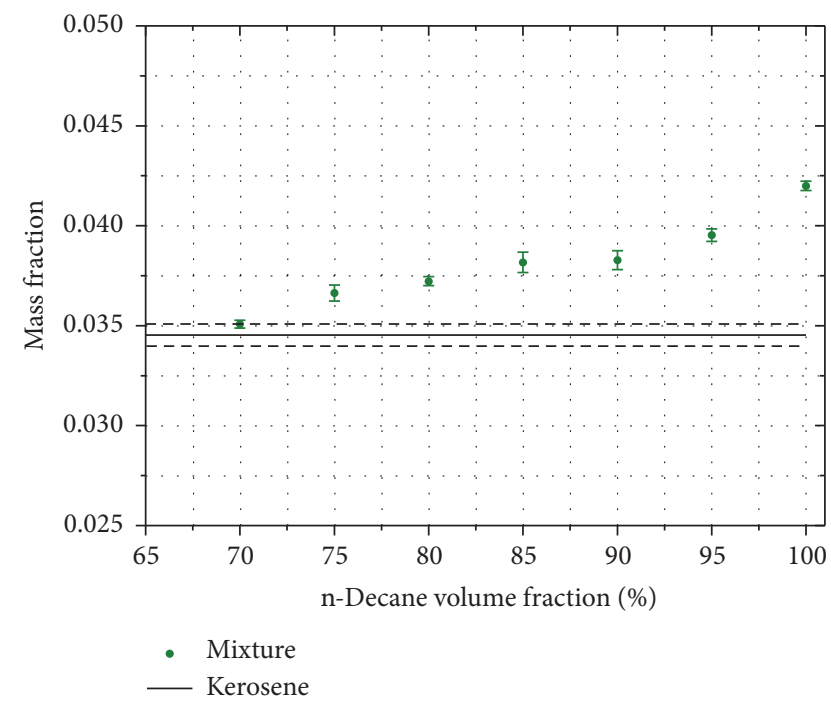

Figure 8: Comparison of mass fraction of $\mathrm{H} 2 \mathrm{O}$ for the surrogate and the kerosene burning.

in mixture reduces evaporation temperature. Therefore, using mixture is improving the spray and evaporation characteristics of fuel. This has led to more efficient combustion and improved combustion efficiency and did not change the average temperature at the outlet and the combustion chamber. Figure 11 shows that the axis of the combustion chamber temperature does not differ by more than $15^{\circ}$. Temperature differs by more than $170^{\circ}$ near the wall. This fact shows the change gas dynamic flow structure inside the combustion chamber also. Gas dynamics for kerosene and surrogate is different. For more accurate prediction of combustion products, the surrogate should be added with a component or a group of components. The obtained mixture should reproduce the physical properties of kerosene: viscosity and drop surface tension. 


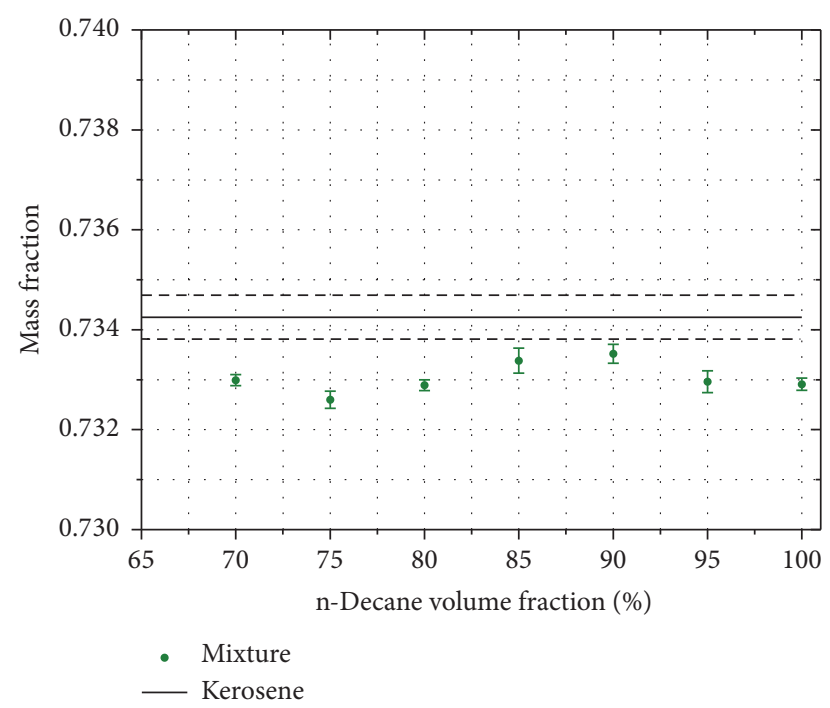

FIGURE 9: Comparison of mass fraction of N2 for the surrogate and the kerosene burning.

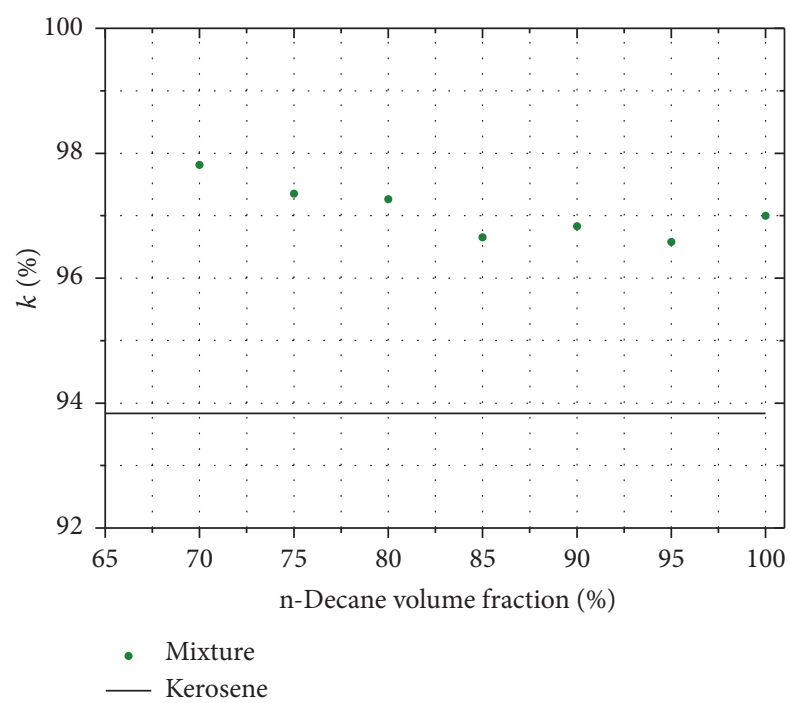

FIGURE 10: Comparison of combustion efficiency for the surrogate and the kerosene burning.

\section{Conclusions}

This paper has studied the effect of adding benzene into the surrogate mixture. The experimental study was carried out in a simulated combustion chamber. The simulated combustion chamber incorporates all major processes going on in commercial combustion chambers. A comparison was made for combustion products of TS-1 aviation kerosene and the surrogate mixture. The study has revealed that use of a mixture of benzene $(20-30 \%)$ and $n$-decane as the fuel gives similar values as compared with the kerosene by the temperature distribution. Combustion efficiency is increased by $4 \%$ also. The emission of pollutants is very different. The emission of pollutants is very different because it is very different gas dynamics by burning kerosene and mixtures. The results are the basis of data for verification CFD models.

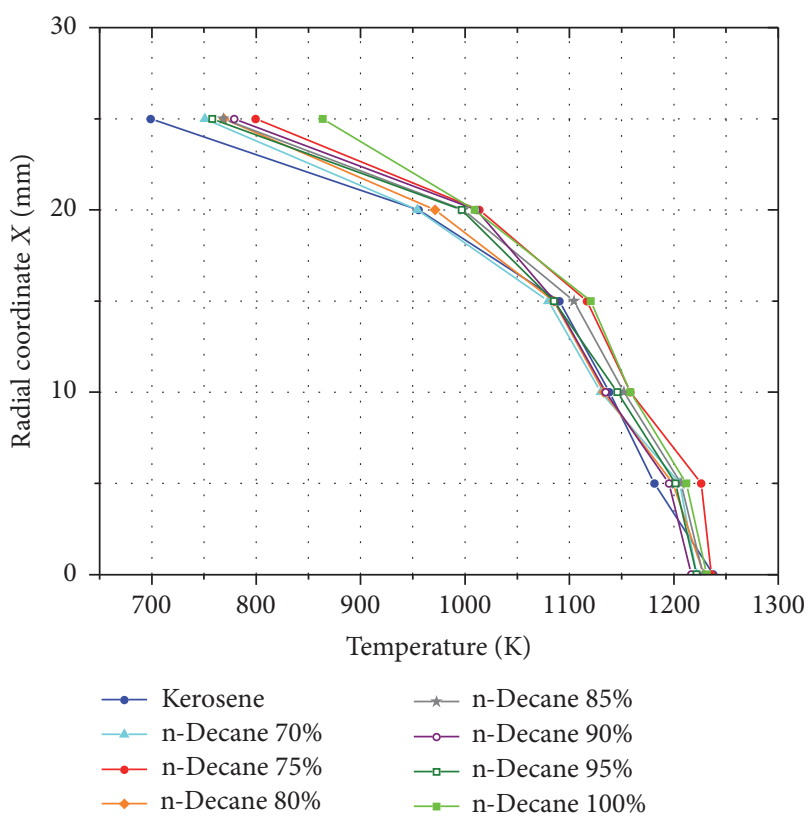

FIGURE 11: Comparison of the temperature for the surrogate and the kerosene burning.

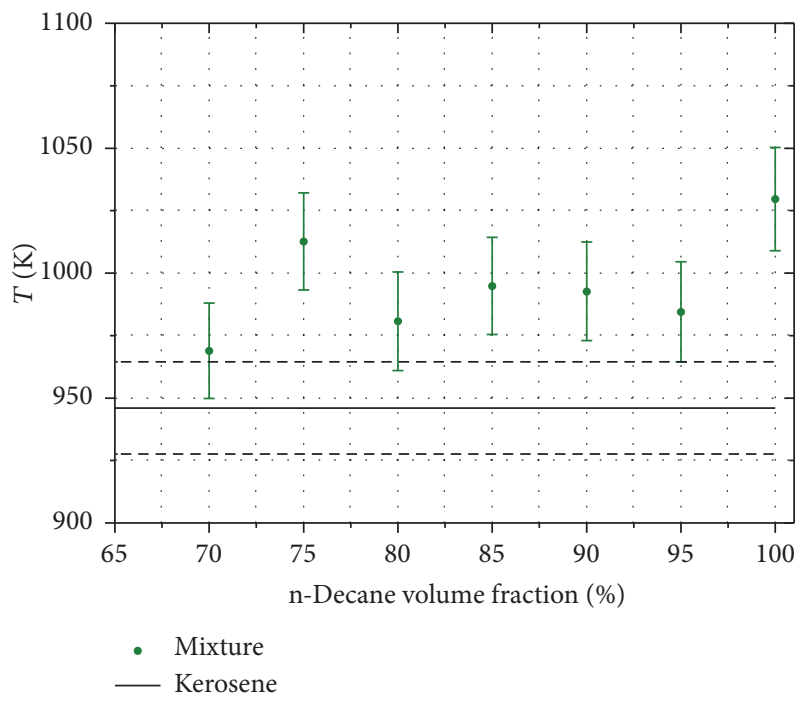

FIgURE 12: Comparison of averaging the temperature for the surrogate and the kerosene burning.

\section{Nomenclature}

CC: Combustion chamber

CFD: Computational fluid dynamics

ICAO: International Civil Aviation Organization

$\varphi$ : $\quad$ Equivalent ratio

$T^{*}: \quad$ Initial temperature

$P^{*}: \quad$ Initial pressure

$G_{\text {air }}$ : Mass air rate

$G_{\text {fuel }}$ : Mass fuel rate. 


\section{Conflicts of Interest}

The authors declare that they have no conflicts of interest regarding the publication of this paper.

\section{Acknowledgments}

This work was supported by the Ministry of Education and Science of the Russian Federation in the framework of the implementation of the Program "Research and Development on Priority Directions of Scientific-Technological Complex of Russia for 2014-2020" (RFMEFI58716X0033). Equipment of CAM technology common use center (RFMEFI59314X0003) was used in these studies.

\section{References}

[1] P. Dagaut, M. Reuillon, J.-C. Boettner, and M. Cathonnet, "Kerosene combustion at pressures up to $40 \mathrm{~atm}$ : Experimental study and detailed chemical kinetic modeling," Symposium (International) on Combustion, vol. 25, no. 1, pp. 919-926, 1994.

[2] T. Edwards and L. Q. Maurice, "Surrogate mixtures to represent complex aviation and rocket fuels," Journal of Propulsion and Power, vol. 17, no. 2, pp. 461-466, 2001.

[3] P. Dagaut, M. Reuillon, M. Cathonnet, and D. Voisin, "High pressure oxidation of normal decane and kerosene in dilute conditions from low to high temperature," Journal de Chimie Physique et de Physico-Chimie Biologique, vol. 92, pp. 47-76, 1995.

[4] R. P. Lindstedt and L. Q. Maurice, "Detailed chemical-kinetic model for aviation fuels," Journal of Propulsion and Power, vol. 16, no. 2, pp. 187-195, 2000.

[5] G. D. Titova, S. M. Frolov, and A. M. Starik, "Kinetic modeling of kerosene/air mixture ignition," in Nonequilibrium Phenomena: Plasma, Combustion, Atmosphere, N. S. Roy, Ed., pp. 271279, 2009.

[6] L. V. Bezgin, V. I. Kopchenov, A. M. Starik, and N. S. Titova, "Modeling studies of ignition and combustion of propane and the products of its thermal destruction in a supersonic air flow," in Pulsed and Continuous Detonations, G. Roy, S. Frolov, and J. Sinibaldi, Eds., pp. 301-307, Torus Press Publishers, 2006.

[7] Survey of jet fuels, "Survey of jet fuels," Report Number A133263, Defense Energy Support Center, Fort Belvoir, VA, USA, 1998.

[8] C. Guéret, M. Cathonnet, J.-C. Boettner, and F. Gaillard, "Experimental study and modeling of kerosene oxidation in a jetstirred flow reactor," Symposium (International) on Combustion, vol. 23, no. 1, pp. 211-216, 1991.

[9] J. V. Soloviova-Sokolova, V. A. Alekseev, S. S. Matveev, I. V. Chechet, S. G. Matveev, and A. A. Konnov, "Laminar burning velocities of benzene + air flames at room and elevated temperatures," Fuel, vol. 175, pp. 302-309, 2016.

[10] V. A. Alekseev, J. V. Soloviova-Sokolova, S. S. Matveev, I. V. Chechet, S. G. Matveev, and A. A. Konnov, "Laminar burning velocities of n-decane and binary kerosene surrogate mixture," Fuel, vol. 187, pp. 429-434, 2017.

[11] S. P. Heneghan, S. P. Heneghan, D. L. Geiger, S. D. Anderson, and W. D. Schulz, "Static tests of jet fuel thermal and oxidative stability," Journal of Propulsion and Power, vol. 9, no. 1, pp. 5-9, 1993.
[12] J. A. Cooke, M. Bellucci, M. D. Smooke et al., "Computational and experimental study of JP-8, a surrogate, and its components in counterflow diffusion flames," Proceedings of the Combustion Institute, vol. 30, pp. 439-446, 2005. 


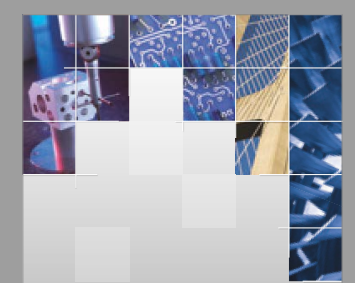

\section{Enfincering}
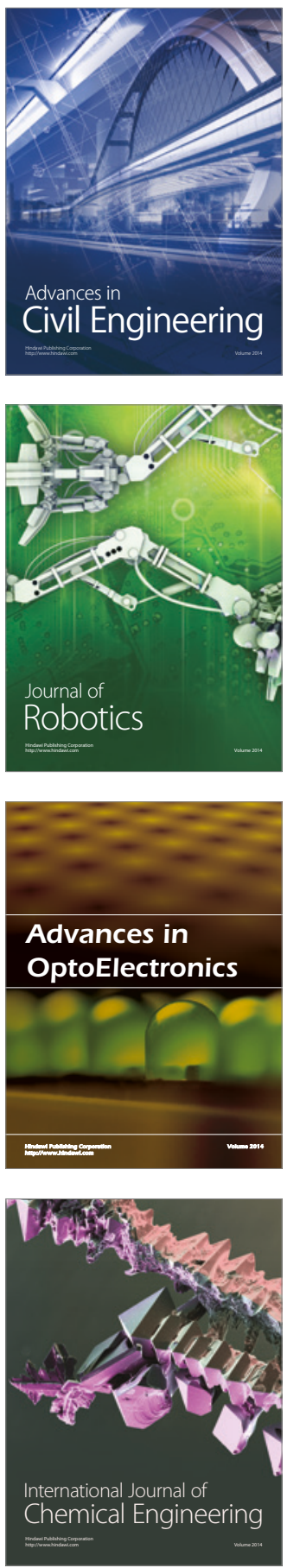

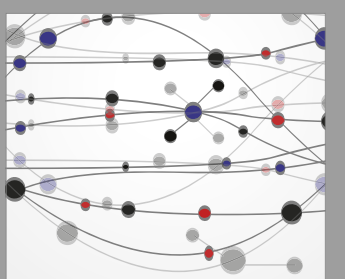

The Scientific World Journal

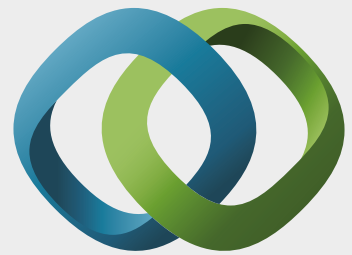

\section{Hindawi}

Submit your manuscripts at

https://www.hindawi.com
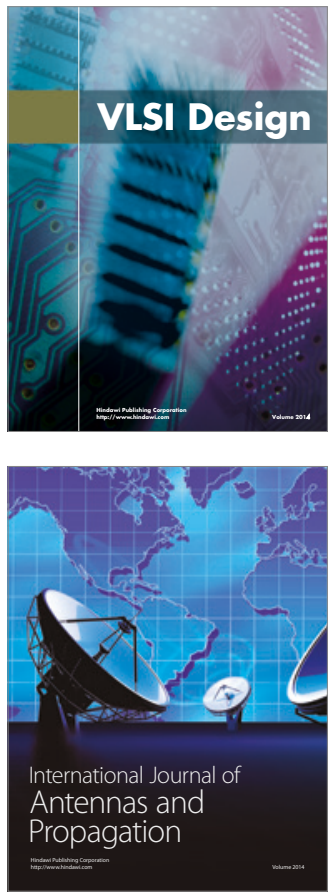

\section{Rotating}

Machinery
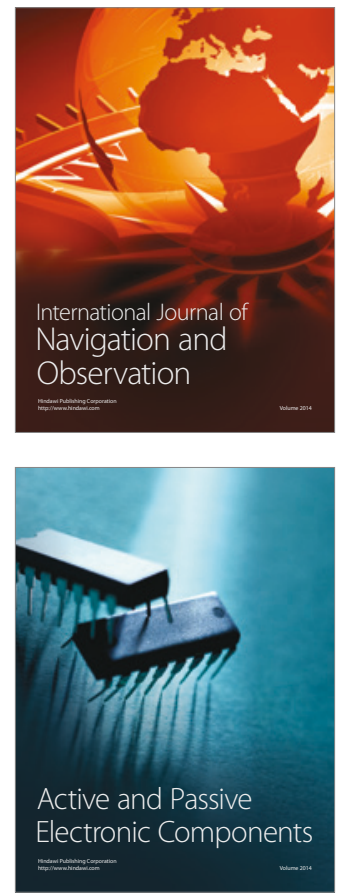
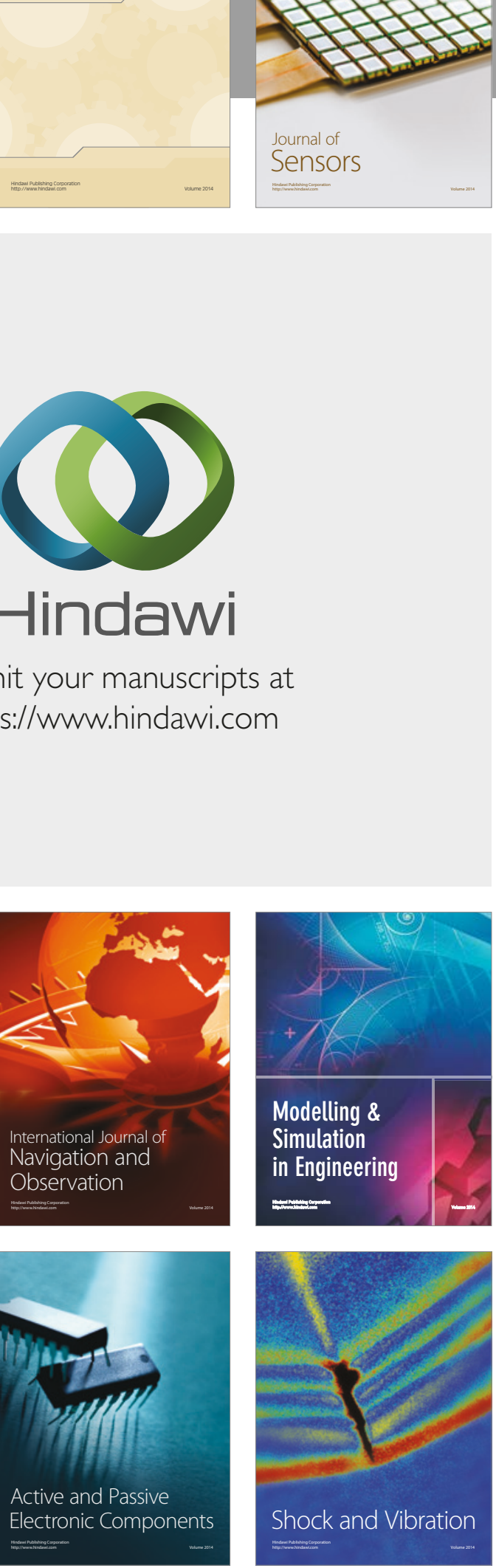
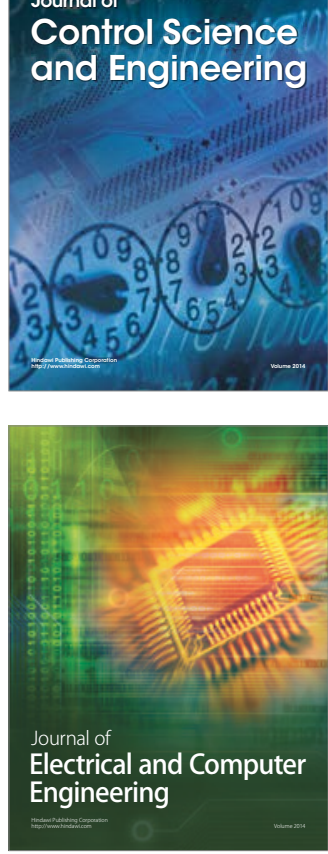

Distributed

Journal of

Control Science

and Engineering
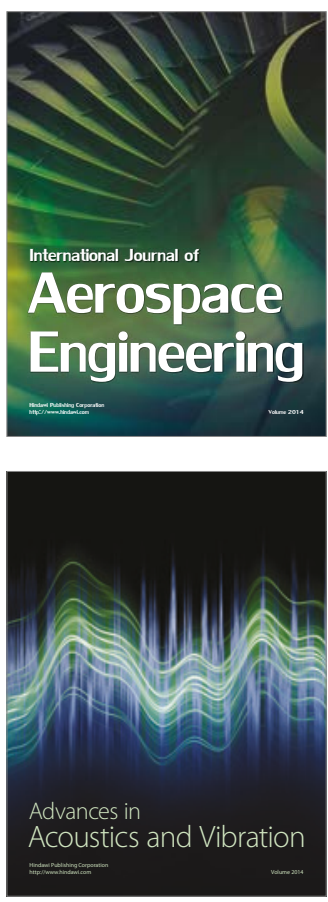

Sensor Networks 